\title{
ANALISIS PENGETAHUAN DAN PERILAKU DUKUN BAYI TERHADAP PROGRAM KEMITRAAN BIDAN DI WILAYAH KERJA PUSKESMAS PAL III SEI JAWI DALAM PONTIANAK TAHUN 2018
}

\author{
Windiyati $^{1}$
}

\author{
Akademi Kebidanan Panca Bhakti Pontianak \\ Email korespondensi: akbidpbpontianak@gmail.com
}

\begin{abstract}
Abstrak
Angka Kematian ibu dan kesakitan ibu hamil, bersalin, nifas serta bayi baru lahir masih merupakan masalah besar di negara berkembang termasuk Indonesia. Survei Demografi Kematian Indonesia (SDKI) tahun 2017 dimana Angka Kematian Ibu (AKI) Indonesia secara Nasional sebesar 305 per 100.000 Kelahiran Hidup. Upaya Making Pregnancy Safer (MPS) dengan 3 pesan kunci yaitu (1) setiap persalinan ditolong oleh tenaga kesehatan terlatih (2) setiap komplikasi obstetrik dan neonatal ditangani mendapat pelayanan adekuat (3) setiap wanita usia subur mempunyai akses terhadap pencegahan kehamilan yang tidak diinginkan dan penanganan komplikasi. Tujuan dalam penelitian ini adalah untuk melakukan analisis pengetahuan dan prilaku dukun bayi terhadap program kemitraan bidan dan dukun di wilayah kerja Puskesmas pal III Sei jawi dalam pontianak Tahun 2018. Penelitian ini menggunakan desain penelitian analitik dengan pendekatan cross sectional. Populasi sejumlah 33 yakni total sampel sebanyak 33 responden. Hasil Penelitian ini didapatkan pengetahuan dukun tentang program kemitraan bidan dan dukun secara umum dikategorikan kurang yaitu sebanyak 21 orang (64\%). Sikap dukun terhadap program kemitraan bidan dan dukun sebagian dari responden 18 orang (54\%) memiliki sikap tidak mendukung terhadap program kemitraan bidan dan dukun. Berdasarkan analisa bivariat hubungan antara pengetahuan dan perilaku dukun tentang program kemitraan bidan dan dukun didapatkan bahwa hasil $\mathrm{X}^{2}$ hitung sebesar 1,26 lebih kecil di bandingkan dengan $\mathrm{X}^{2}$ tabel 5,99 sehingga dapat di tarik kesimpulan bahwa Ha di tolak dan Ho di terima. Artinya tidak terdapat hubungan antara pengetahuan dengan prilaku dukun terhadap program kemitraan dukun dan bidan. Saran pada penelitian ini agar tenaga kesehatan dapat memberikan pengetahuan dengan mengumpulkan kembali seluruh dukun dan mengenalkan kembali tentang program kemitraan bidan dan dukun, memberikan penyuluhan tentang program bidan agar dukun mengerti dan mau memahami serta bekerja sama dengan bidan dalam program mitra bidan dan dukun.
\end{abstract}

Kata Kunci: Pengetahuan, sikap, dukun, program kemitraan bidan dan dukun

\section{Pendahuluan}

Untuk menurunkan angka kematian ibu (AKI) dari 305/100.000 kelahiran hidup pada tahun 2018/2019 diharapkan tahun 2024 menjadi 183 per 100.000 kelahiran hidup dan AKB per 100.000 kelahiran hidup merupakan sasaran yang hendak dicapai pemerintah Indonesia dalam pencapaian Millenium Development Goals (MDGs). Target ini sampai saat ini belum tercapai karena angka kematian ibu masih tinggi. Hasil Survei Demografi Kesehatan Indonesia (SDKI) tahun 2018 menunjukkan bahwa angka kematian ibu mencapai 305/100.000 kelahiran hidup. Pada

\footnotetext{
${ }^{1}$ Dosen Akademi Kebidanan Panca Bhakti Pontianak
}

tahun 2015 sebagai perbandingan, Malaysia telah menurunkan hingga $45 \%$ dalam 20 tahun terakhir. Salah satu daerah dengan AKI yang cukup tinggi adalah Kalimantan barat .kota pontianak.

Provinsi Kalimantan Barat ( KalBar) Kematian ibu mencapai 113 per 100.000 kelahiran hidup. Jika dilihat tahun 2017 terdapat kasus kematian ibu sebesar 98 kasus dan hal ini masih merupakan masalah besar di negara berkembang termasuk Indonesia. WHO (World Health Organization) memperkirakan diseluruh dunia setiap 
tahunnya lebih dari 585.000 ibu meninggal pada saat hamil atau bersalin.

Upaya Making Pregnancy Safer (MPS) dengan 3 pesan kunci yaitu (1) setiap persalinan ditolong oleh tenaga kesehatan terlatih (2) setiap komplikasi obstetrik dan neonatal ditangani mendapat pelayanan adekuat (3) setiap wanita usia subur mempunyai akses terhadap pencegahan kehamilan yang tidak diinginkan dan penanganan komplikasi (Depkes, 2017).

Trend AKI Indonesia secara Nasional dari tahun 1994 sampai dengan tahun 2015, dimana menunjukkan penurunan yang signifikan dari tahun ke tahun yaitu dari 390 menjadi 102/100.000 kelahiran hidup. Terkait masalah tersebut, pemerintah mengembangkan program kemitraan dukun dan bidan dengan tujuan alih fungsi peran dukun yang awalnya menolong persalinan menjadi rekan bidan dalam memantau perkembangan kesehatan ibu selama periode kehamilan sampai masa nifas. Meskipun kemitraan dukun dan bidan di Indonesia termasuk di kota pontianak khususnya puskesmas pal III telah berjalan sejak lama,akan tetapi sampai saat ini masih banyak yangbelum terlaksana dengan baik.

Berdasarkan data dari Dinas Kesehatan Kalimantan Barat, angka kematian ibu masih sangat tinggi pada tahun 2017 dimana terjadi AKI 98 kasus pada 100.000 kelahiran hidup. Masih ada persalinan yang ditolong oleh non tenaga kesehatan atau dukun bayi. Dukun bayi atau dukun beranak adalah seorang anggota masyarakat yang mendapat kepercayaan serta ketrampilan menolong persalinan secara tradisional dan mendapat ketrampilan tersebut secara turun temurun. Sampai saat ini Indonesia masih ada pertolongan persalinan dilakukan oleh dukun bayi yang masih menggunakan cara-cara tradisional sehingga banyak merugikan dan membahayakan keselamatan ibu dan bayi. Di beberapa daerah keberadaan dukun bayi sebagai orang kepercayaan dalam menolong persalinan, sosok yang dihormati dan berpengalaman. Berbeda dengan bidan yang rata-rata masih muda dan belum seluruhnya mendapatkan kepercayaan masyarakat.

Upaya pemerintah untuk menurunkan AKI/ AKB salah satunya adalah program kemitraan dukun dan bidan yaitu suatu bentuk kerjasama bidan dengan dukun yang saling menguntungkan dengan prinsip keterbukaaan, kesetaraan, dan kepercayaan dalam upaya untuk menyelamatkan ibu dan bayi, dengan menempatkan bidan sebagai penolong persalinan dan mengalih fungsikan dukun dari penolong persalinan menjadi mitra dalam merawat ibu dan bayi pada masa nifas, berdasarkan kesepakatan yang telah dibuat antara bidan dengan dukun, serta melibatkan seluruh unsur atau elemen masyarakat yang ada (Depkes, 2015).

Penelitian yang dilakukan oleh Rukmini (2016) tentang Persepsi Dukun Bayi Terhadap Kemitraan Dengan Bidan Dalam Pertolongan Persalinan di Pedesaan di Provinsi Jawa Timur dan Kalimantan Selatan dimana hasilnya dari 40 responden $80 \%$ $100 \%$ sudah melakukan kemitraan dengan 
bidan setempat. Penelitian tentang Dukun Bayi Dalam Persalinan Oleh Masyarakat Indonesia dilakukan oleh Rina Anggorodi (2017) di Kendari dan Jawa Barat dengan metode kualitatif menggunakan wawancara mendalam terhadap dukun bayi, bidan dan ibu yang melahirkan ditolong oleh bidan dan dukun. Dimana kesimpulan dari penelitian tersebut adalah usaha-usaha peningkatan pelayanan kesehatan seperti yang tercermin dalam program dukun latih ini memang bukan bertujuan untuk menghilangkan peranan yang dimainkan oleh sistem perawatan kesehatan yang lama dan menggantinya dengan system perawatan kesehatan yang baru.

Kemitraan merupakan salah satu solusi untuk menurunkan masalah kematian ibu dan bayi yang terutama akan menguntungkan daerah-daerah terpencil dimana akses terhadap pelayanan kesehatan sangat terbatas (Anggorodi, 2007). Dukun yang melakukan pertolongan persalinan secara mandiri.Beberapa laporan penelitian mengenai kemitraan dukun dan bidan,seperti laporan penelitian Afrisal dan Yasir di Kabupaten jawa timur menemukan bahwa ada hubungan yang bermakna antara kemitraan bidan dan dukun terlatih dengan peningkatan cakupan pertolongan persalinan oleh tenaga kesehatan. Lebih lanjut, laporan penelitian oleh mustakim tahun 2012 menyebutkan bahwa ada hubungan antara pengetahuan, ketersediaan fasilitas dan regulasi dengan kemitraan bidan dan dukun.

Data tahun 2017 Puskesmas pal III memiliki 33 orang dukun yang pernah dilakukan kemitraan bidan dan dukun pada tahun 2016 sebanyak 12 orang, sedangkan 21 orang dukun belum pernah mendapatkan program kemitraan tersebut. Data bulan Januari sampai dengan Maret 2012 ada 12 kasus yang dirujuk oleh dukun ke bidan/ Puskesmas diantaranya: 7 kasus retentio placenta, 2 kasus perdarahan, 2 kasus KPD dan 1 kasus bayi letak bokong. Dukun merujuk pasien ketika mereka sudah tidak mampu menangani sendiri kasus penyulit dalam persalinan yang dihadapi. Dari data diatas dapat disimpulkan bahwa masih ada dukun yang tidak mau bermitra atau bekerjasama dengan bidan dengan tidak mau merujuk pasien ke bidan, ataupun terpaksa merujuk karena tidak mampu lagi menangani penyulit dalam persalinan.

Berdasarkan latar belakang tersebut diatas maka dilakukan penelitian denagn topik "Analisis Pengetahuan Dan prilaku dukun bayi Terhadap Program Kemitraan Bidan Dan Dukun Di Wilayah Kerja Puskesmas Pal III.Sei jawi dalam Kota Pontianak. Tahun 2018.

\section{Metode}

Penelitian ini menggunakan desain penelitian analitik kuantitatif dengan pendekatan cross sectional. Penelitian ini dilakukan di wilayah kerja puskesmas Pal III sei jawi dalam Kota pontianak. Populasi dalam penelitian ini adalah seluruh dukun di wilayah Puskesmas Sosok Kecamatan Tayan Hulu Kabupaten Sanggau bulan Februari 2012 berjumlah 33 orang dan peneliti mengambil total populasi yaitu 33 responden. 
Hasil dan Pembahasan

Tabel 1. Analisa Univariat

\begin{tabular}{lcc}
\hline \multirow{2}{*}{ Kategori } & \multicolumn{2}{c}{ Hasil } \\
\cline { 2 - 3 } & $\mathrm{N}$ & $\%$ \\
\hline Pengetahuan & 4 & 12 \\
$\quad$ Baik & 8 & 24 \\
Cukup & 21 & 64 \\
Kurang & & \\
Perilaku & 15 & 46 \\
Mendukung & 18 & 54 \\
Tidak Mendukung & & \\
\hline
\end{tabular}

Berdasarkan tabel 1 di atas kategori tingkat pengetahuan tentang program kemitraan bidan dan dukun sebagian besar dari responden 21 orang (64\%) dengan kategori kurang dan sangat sedikit dari responden 4 orang (12\%) dikategorikan baik, sedangkan pada kategori perilaku dapat diketahui bahwa sebagian dari responden 18 orang (54\%) tidak mendukung terhadap program kemitraan bidan dan dukun.

Tabel 2. Analisa Bivariat

\begin{tabular}{|c|c|c|c|c|c|}
\hline \multirow{2}{*}{ Prilaku } & \multicolumn{3}{|c|}{ Pengetahuan } & \multirow{2}{*}{$\mathrm{X}^{2}$ tabel } & \multirow{2}{*}{$\mathrm{X}^{2}$ hitun } \\
\hline & Baik & Cukup & Kurang & & \\
\hline $\mathrm{Ya}$ & 2 & 5 & 8 & & \\
\hline Tidak & 2 & 3 & 13 & 5,99 & 1,26 \\
\hline Rata-Rata & 4 & 8 & 21 & & \\
\hline
\end{tabular}

Berdasarkan analisa bivariat hubungan antara pengetahuan dan perilaku dukun tentang program kemitraan bidan dan dukun didapatkan bahwa hasil $\mathrm{X}^{2}$ hitung sebesar 1,26 lebih kecil di bandingkan dengan $\mathrm{X}^{2}$ tabel 5,99 sehingga dapat di tarik kesimpulan bahwa $\mathrm{Ha}$ di tolak dan Ho di terima. Artinya tidak terdapat hubungan antara pengetahuan dengan prilaku dukun terhadap program kemitraan dukun dan bidan.

Berdasarkan dari hasil penelitian yang menggunakan kuesioner di dapat bahwa pengetahuan responden tentang program kemitraan bidan dan dukun secara umum dengan jumlah responden 33 didapatkan hasil sebagian besar dari responden 21 orang (64\%) dengan kategori kurang, sangat sedikit dari responden 8 0rang (24\%) dengan kategori cukup dan sangat sedikit dari responden 4 orang $(12 \%)$ dikategorikan baik.

$$
\text { Menurut Notoatmodjo }
$$
pengetahuan yang tercakup dalam domain kognitif mempunyai beberapa tingkatan yaitu: Tahu (Know), memahami (Comprehension), aplikasi (Application), analisis (Analysis), sintesis (Synthesis) dan evaluasi (Evaluation).

Dilihat dari hasil penelitian sebagian besar dari responden 21 orang (64\%) dengan kategori kurang dan dari jawaban pertanyaan nomor 6, 11 dan 12 yang sangat sedikit menjawab benar, dapat disimpulkan bahwa responden dalam tingkat pengetahuan ratarata berada pada tingkat Tahu (Know), menurut Notoatmodjo (2003) "Tahu" 
merupakan tingkat pengetahuan yang paling rendah karena hanya mengingat memori sebelumnya tanpa memahami, mengaplikasikan dan menganalisanya.

Pengetahuan dukun di wilayah kerja Puskesmas pal III masih kurang karena pada saat pihak Puskesmas Pal III melaksanakan pembinaan kemitraan bidan dan dukun. Ternyata masih ada sebagian dari dukun yang tidak hadir dan tidak ada respon positif terhadap kemitraan bidan dan dukun.

Berdasarkan hasil penelitian dengan mengunakan kuesioner sebagian dari responden 18 orang (54\%) tidak mendukung terhadap program kemitraan bidan dan dukun dan sebagian dari responden 15 orang (45\%) mendukung terhadap program kemitraan bidan dan dukun.

Hasil penelitian di atas berbeda dengan penelitian yang dilakukan oleh Rukmini (2006) tentang Persepsi Dukun Bayi Terhadap Kemitraan Dengan Bidan Dalam Pertolongan Persalinan di Pedesaan di Provinsi Jawa Timur dan Kalimantan Selatan dimana hasilnya dari 33 responden $80 \%-100 \%$ sudah melakukan kemitraan dengan bidan setempat.

Dari pernyataan mengenai prilaku dukun di wilayah kerja Puskesmas Pal III tidak mendukung dalam kemitraan bidan dan dukun karena ketidaktahuan mereka tentang fungsi kemitraan, selain itu jarak ke tempat pelayanan kesehatan yang jauh, keterikatan budaya dengan masyarakat setempat serta menambah pendapatan dukun dan ini mempengaruhi terhadap pelayanan kesehatan.
Dilihat dari hasil penelitian bahwa sebagian dari responden 18 orang (54\%) memiliki prilaku tidak mendukung terhadap program kemitraan bidan dan dukun dan sebagian dari responden 15 orang (45\%) mendukung terhadap program kemitraan bidan dan dukun, maka arah prilaku menurut Azwar (2009) dimana jika orang yang tidak setuju pada objek tertentu atau tidak mendukung dikatakan memiliki prilaku yang arahnya negatif. Hal ini dapat dipengaruhi oleh beberapa faktor (Wawan, 2010) yaitu pengalaman pribadi, pengaruh orang lain yang dianggap penting, pengaruh kebudayaan, media massa, lembaga pendidikan dan lembaga agama serta faktor emosional.

Hal ini juga yang mendasari prilaku responden diatas dimana geografis, luas wilayah dan faktor ekonomi juga menjadi salah satu penyebab dari prilaku dukun, selain itu sosial budaya setempat juga ikut andil dalam dukun menentukan sikap dan prilaku karena beranggapan mereka lebih mengetahui adat istiadat dalam persalinan. Prilaku adalah tindakan atau aktifitas dari manusia itu sendiri yang mempunyai bentangan arti yang sangat luas . atau semua kegiatan atau aktifitas yang diamati langsung.maupun yang tidak dapat diamati (Notoadmojo.2003).

Pengetahuan sangat berpengaruh dan berhubungan dengan prilaku dan sikap seseorang, karena pengetahuan adalah merupakan hasil "tahu" dan ini terjadi setelah orang melakukan penginderaan terhadap suatu obyek tertentu. Penginderaan melalui panca indra yakni penglihatan, pendengaran, 
penciuman, rasa dan raba. Sebagian besar pengetahuan manusia diperoleh melalui mata dan telinga. Pengetahuan atau kognitif merupakan dominan yang sangat penting untuk terbentuknya sikap atau tindakan seseorang (overt behavior) (Notoatmodjo, 2003).

Hal ini sangat bertolak belakang dengan hasil penelitian ini dimana 10 responden yang pengetahuannya kurang tetapi prilaku mereka mendukung dan ada 2 responden yang pengetahuan mereka baik namun prilaku mereka tidak mendukung terhadap kemitraan bidan dan dukun. Selain itu dari jawaban yang diperoleh, dapat dilihat bahwa budaya kepercayaan masyarakat didaerah terhadap dukun bayi masih tetap ada. Meskipun layanan kesehatan primer.seperti puskesmas sudah tersedia,keberadaan dukun bayi tak bisa dihilangkan sepenuhnya.

Temuan ini sesuai dengan Notoadmojo 2013 mengatakan bhawa prilaku seseorang dapat dipengaruhi oleh beberapa faktor yaitu :persepsi, motivasi, emosi dan belajar. Dimana persepsi: adalah sebagai pengalaman yang dihasilkan melalui indera penglihatan,pendengaran,penciuman, dan motivasi : sebagai dorongan untuk bertindak untuk mencapai suatu tujuan tertentu., selanjutnya emosi : aspek psikologi yang mempengaruhi emosi berhubungan erat dengan keadaan jasmani serta belajar : pembentukan prilaku dihasilkan dari praktek praktek dalam lingkungan kehidupan dan belajar dapat dikatakan sebagai mendapat pengetahuan. Oleh karena itu prilaku sangat erat kaitan dan hubungannya dengan pengetahuan.

Faktor ekonomi juga menjadi salah satu penyebab dari prilaku dukun yang tidak mendukung karena itu merupakan pendapatan dari dukun itu sendiri, selain itu sosial budaya setempat juga ikut andil dalam dukun menentukan sikap karena beranggapan mereka lebih mengetahui adat istiadat dalam persalinan.

Program Kemitraan Bidan dan Dukun merupakan salah satu program sebagai upaya untuk meningkatkan cakupan pertolongan persalinan oleh tenaga kesehatan. Definisi Kemitraan Bidan dan Dukun sendiri adalah suatu bentuk kerjasama bidan dan dukun yang saling menguntungkan dengan prinsip keterbukaan, kesetaraan dan kepercayaan dalam upaya untuk menyelamatkan ibu dan bayi, dengan menempatkan bidan sebagai penolong persalinan dan mengalih fungsikan dukun dari penolong persalinan menjadi mitra dalam merawat ibu dan bayi pada masa nifas, dengan berdasarkan kesepakatan yang telah dibuat antara bidan dan dukun serta melibatkan seluruh unsur/elemen masyarakat yang ada (Depkes, 2011)

Dalam proses alih peran dan pembagian tugas antara Bidan dengan dukun perlu disepakati mekanisme kemitraan yang dijalin antara mereka. Meskipun mekanisme sangat beragam tergantung keadaan, tetapi ada beberapa hal penting yang harus disepakati (dituangkan secara tertulis dalam nota kesepakatan antara bidan dan dukun) yaitu: mekanisme rujukan informasi ibu hamil, 
mekanisme rujukan kasus persalinan, mekanisme pembagian biaya persalinan dan jadwal pertemuan rutin bidan dengan dukun.

Puskesmas pal III telah melakukan pelatihan dan penyuluhan terhadap dukun yang sudah terlatih maupun yang belum terlatih, namun hasil dari penelitian menyatakan bahwa pengetahuan responden yang sebagian besar dikategorikan kurang sehingga perlu adanya penyegaran kembali kepada para dukun tentang program kemitraan bdan dan dukun secara terus menerus. Di dukung dengan hasil prilaku dan sikap pada penelitian dimana prilaku responden yang sebagian tidak mendukung program kemitraan bidan dan dukun,

\section{Kesimpulan}

Hasil penelitian ini menyatakan bahwa tidak terdapat hubungan antara pengetahuan dengan prilaku dukun terhadap program kemitraan di puskesmas Pal III tahun 2018. Demi menigkatkan kepercayaan masyarakat didaerah terhadap bidan, perbaikan kualitas pelayanan bidan perlu ditingkatkan, seperti perbaiki kualitas bidan, jadi bidan juga harus ramah,upayanya mendekatkan dan mengenalkan bidan ke masyarakat.Bidan diajak bertemu langsung ke masyarakat.

\section{Daftar Pustaka}

Anggorodi, R. 2009. Dukun Bayi Dalam Persalinan Oleh Masyarakat Indonesia, Volume 13 Jakarta: Makara Kesehatan

Arikunto, S. 2010. Prosedur Penelitian Suatu Pendekatan Praktis. Edisi Revisi.
Cetakan keempat belas. Jakarta: Rineka Cipta

Arikunto, S. 2006. Prosedur Penelitian Suatu Pendekatan Praktis. Edisi Revisi VI. Cetakan ketiga belas. Jakarta: Rineka Cipta

Azwar, S. 2009. Sikap Manusia, Teori dan Pengukurannya. Edisi kedua. Yogyakarta: Penerbit Pustaka Pelajar

Depkes RI. 1994. Pedoman Revisi Dukun. Jakarta: Direktorat Pembinaan Kesehatan Masyarakat

. 2015. Pedoman Kemitraan Bidan
Dukun.
www.kesehatanibu.depkes.go.id/wp-
content/.../download.php?id=2,
Diakses: 11 Februari 2012, 10.00 WIB
2015. Program Kemitraan Bidan
dan Dukun.
http://www.kesehatanibu.depkes.go.id/
archives/126, Diakses: 11 Februari
2018, 10.00 WIB

Dinkes pontianak. 2011. Profil Dinas Kesehatan kota Pontianak.Tahun 2017.

Notoatmodjo, S. 2003. Ilmu Kesehatan Masyarakat. Jakarta: Rineka Cipta 2007. Promosi Kesehatan dan Ilmu Perilaku. Jakarta: Penerbit Rineka Cipta

Prawirahardjo, S. 2005. Ilmu Kebidanan. Jakarta: YBPSP

Puskesmas Pal III. 2011. Profil Puskesmas Pal III

Rukmini. 2006. Persepsi Dukun Bayi Terhadap Kemitraan Dengan Bidan Dalam Pertolongan Persalinan Dipedesaan di Provinsi Jawa Timur dan Kalimantan Selatan. http://jurnal.pdii.lipi.go.id/admin/jurnal /. Diakses: 11 Februari 2018, 11.00 WIB 
Saryono, A, S. 2010. Metodologi Penelitian Kebidanan D III, D IV, SI dan S2. Yogyakarta: Nuha Medika

Sugiyono. 2010. Metode Penelitian Kuantitatif, Kualitatif dan R\&D. Cetakan Kesebelas. Bandung: Penerbit Alfabeta

Wawan, A. \& Dewi, M. 2010. Teori \& Pengukuran Pengetahuan, Sikap dan Prilaku Manusia. Yogyakarta: Nuha Medika 